\title{
Netzwerk Teilchenwelt: Where High School Students Participate in HEP Research and Young Talents are Promoted
}

\author{
Uta Bilow ${ }^{1}$ \\ Technische Universität Dresden \\ Institute for Nuclear and Particle Physics, TU Dresden, 01062 Dresden, Germany \\ E-mail: uta.bilowetu-dresden.de

\section{Michael Kobel} \\ Technische Universität Dresden \\ Institute for Nuclear and Particle Physics, TU Dresden, 01062 Dresden, Germany \\ E-mail: michael.kobeletu-dresden. de
}

To enable high school students to participate in the fascinating research in HEP physics, 30 universities in Germany have joined forces to form Netzwerk Teilchenwelt. About 150 researchers are active in the outreach program and bring cutting edge physics research into the classroom, for example with Masterclasses. They inform high school students about current findings, open questions and research methods in particle and astroparticle physics. Every year about 4000 students are reached and work with original data from CERN or study cosmic particles with particle detectors. In the advanced stages of Netzwerk Teilchenwelt, motivated pupils continue to engage in research and attend workshops at CERN. The most committed students can spend two weeks at CERN doing their own research projects. Preparation and follow-up of this work takes place close to home. The finished projects are usually taken to the Abitur (university entrance qualification) or competition entries, e.g. Jugend forscht, and are often awarded prestigious prizes.

Through a fellow program, young people who found their way to particle physics via Netzwerk Teilchenwelt are further supported as students. The program offers students early contact with research at their place of study, personal support and further education, as well as nationwide networking opportunities. Through the fellow program, research groups can attract highly motivated and educated young scientists who can take on future research and development tasks, but also help with scientific activities such as conferences or outreach events. Since 2019, Netzwerk Teilchenwelt has joined forces with other players in the BMBF-funded KONTAKT project, e.g. Weltmaschine, in order to expand the range of programs to include topics of hadrons and nuclear physics on the one hand and to address other target groups such as the general public and journalists on the other.

European Physical Society Conference on High Energy Physics - EPS-HEP2019 -

10-17 July, 2019

Ghent, Belgium

\section{${ }^{1}$ Speaker}




\section{Motivation}

Many high school students have numerous interests and talents. For example, they like to learn languages, are interested in natural sciences and history, do sports and play a musical instrument. These young people, who are interested and motivated in many things, are potential young talents for HEP. But how can they be inspired for a career in HEP? In general, there are three possibilities. First, we can wait and see which path the students will take and in which direction they will develop. Secondly, you can give them material about research at CERN and tell them about it. Or thirdly, and in our opinion this is the best way: they get the chance to participate in research and can carry out various activities, e.g. internships, Masterclasses (1-day workshops for high school students, analyzing data from LHC experiments) [1], workshops at CERN, or own research projects. Then it is no longer left to chance which of their talents they develop. But it becomes more likely that they will decide to study physics and start a career in HEP.

\section{Introduction to Netzwerk Teilchenwelt}

\subsection{A Network Comprising 30 German Universities and Research Institutes}

In Germany, Netzwerk Teilchenwelt [2] runs such a support program for young people and the recruitment of young talent. For this program, 30 universities and research institutes have joined forces with CERN. Students between the ages of 15 and 19 can get to know HEP research at Netzwerk Teilchenwelt and take part in it themselves. In a multi-stage program, young people can work with original CERN data or carry out their own measurements with particle detectors. About 3.500 pupils take part in the basic program each year, 350 pupils are involved in the higher levels. Netzwerk Teilchenwelt was launched in 2010; the project team works at TU Dresden, DESY in Zeuthen, and CERN.

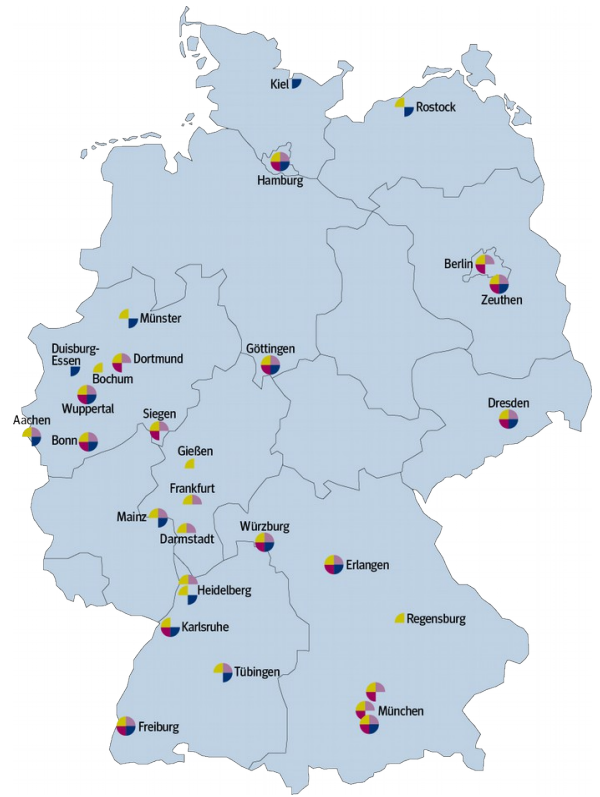

Figure 1: Netzwerk Teilchenwelt comprises 30 research institutes 


\subsection{Various Offers for High School Students}

In the basic program, high school students can take part in a particle physics Masterclass and analyze data from the LHC experiments ALICE, ATLAS, CMS, or LHCb. A Masterclass is a 1-day workshop, where pupils become "particle physicists for a day." They learn more about particle physics from a mentor before making a measurement based on authentic data from a contemporary experiment. Masterclasses with data from the Pierre Auger Observatory or the IceCube neutrino telescope are also offered. The web portal Cosmic@web provides access to data sets from astroparticle physics experiments, which are located on the research vessel Polarstern or the Neumayer-Station [3]. With special detectors (Cherenkov or scintillation detectors) own data can be taken and different measurement tasks can be processed.

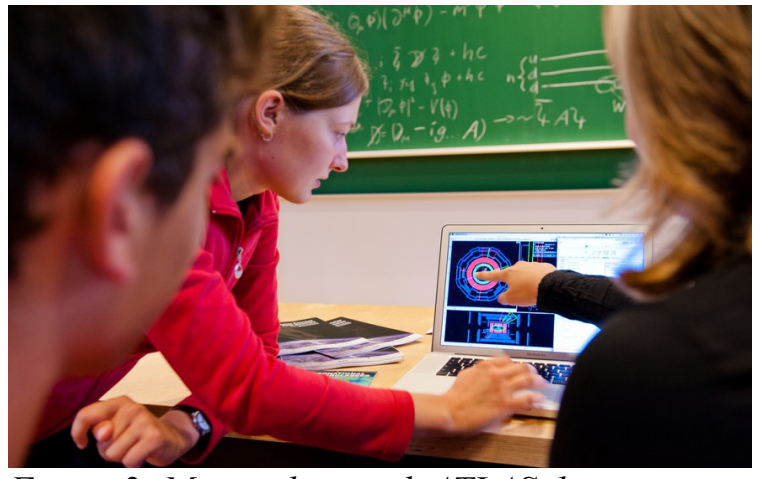

Figure 2: Masterclass with ATLAS data (CJuliana Socher)

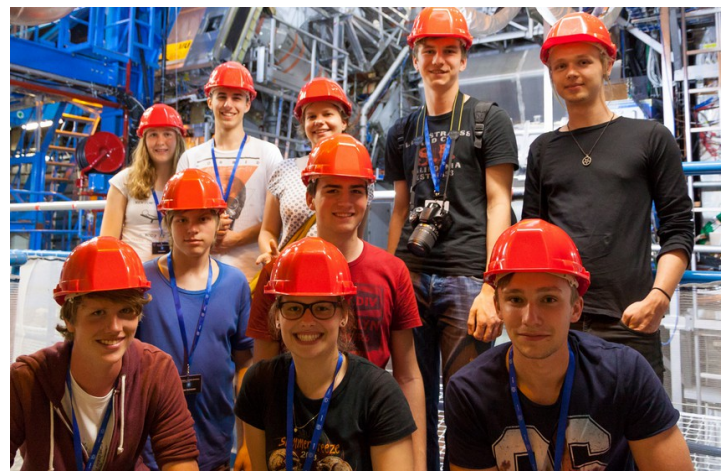

Figure 3: High school students visiting CERN

\subsection{Workshops and Research Projects at CERN}

Highly motivated students can take part in a workshop at CERN, where they can gain indepth experience with research during a 4-day-stay. And finally, some particularly committed students prepare their own research work, which they then contribute to their graduation from high school ("Abitur", university entrance qualification), for example. For this work, the students can spend up to two weeks working in a research group at CERN, while preparation and follow-up work take place at a research institute near their home. Many of these works have already won prizes in national competitions, such as "Jugend forscht" [4].

\subsection{Supporting Talents at University}

In an evaluation of the program, it was found that a considerable proportion of the high school students who had applied to take part in a CERN workshop subsequently started studying physics at university and were still interested in particle physics. Therefore, a so-called Fellow Program [5] has been launched in 2017 in order to support and promote young people during their transition to university. All high school students who had applied to take part in a CERN workshop in previous years were invited to register for the program. The Fellow program currently has about 150 participants. The program offers them access to the particle physics research groups via internships or regulars' tables. These in turn benefit from the Fellows' highly motivated and pre-educated students for support in scientific or outreach activities, as well as 
young scientists for their research groups. The Fellows receive an opportunity for nationwide networking via an annual meeting, and they receive professional support via an annual Fellow/Bachelor School in Particle Physics, which was held in spring 2019 for the first time.

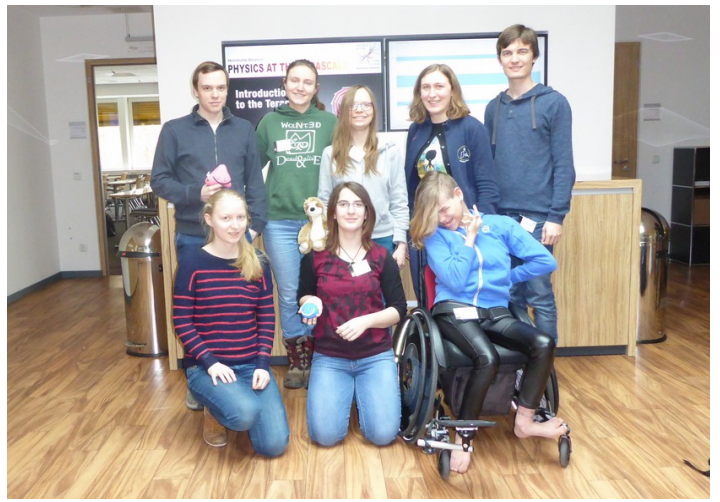

Figure 4: Fellows attending the bachelor school

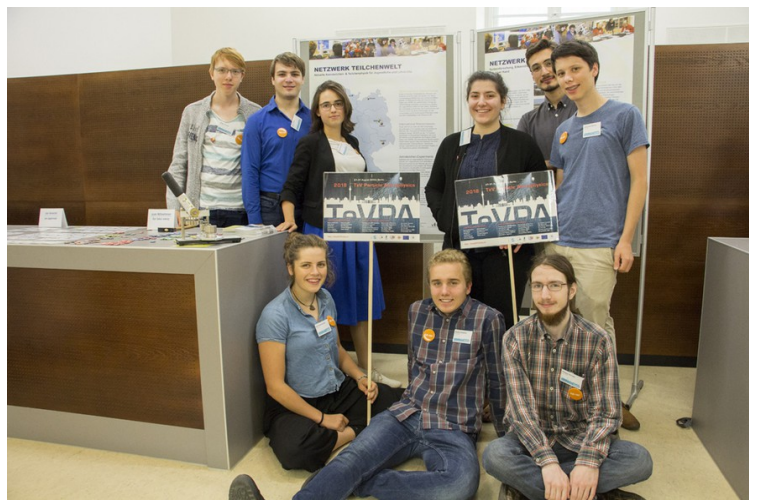

Figure 5: Fellows assisting at the TeVPA conference (CDESY by Ashley Jones)

\section{More Groups involved}

\subsection{PhD students as Role Models}

All activities for pupils are usually carried out by $\mathrm{PhD}$ students as so-called "masters". They hold Masterclasses, explain to the students how the particle detectors work, and supervise the student research work. At the same time, they act as role models. In return, they receive a fee and travel expenses. The Masterclasses are normally held in the schools. This reduces the organizational effort and allows the offers of Netzwerk Teilchenwelt to reach the region - they are quasi mobile. Netzwerk Teilchenwelt offers a soft skill course for the $\mathrm{PhD}$ students with contents from science communication, didactics and presentation techniques, which are also beneficial for the further career [6].

\subsection{Programs for Teachers}

Teachers are addressed as multipliers via other programs. Here, extensive context and teaching material was developed, such as a four-volume teaching series on particle physics [7], a card game with particle profiles [8] and a new chapter for the physics teaching platform "LEIFI-Physik" [9], which is very popular among teachers and students in Germany. In addition, two-day teacher training courses are held several times a year as well as a one-week summer school for 20 teachers at CERN [10]. 


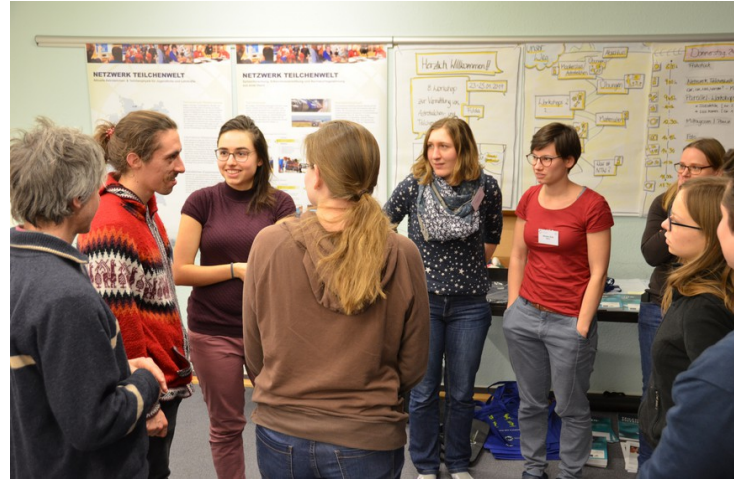

Figure 6: PhD students at the soft skill course practise in science communication

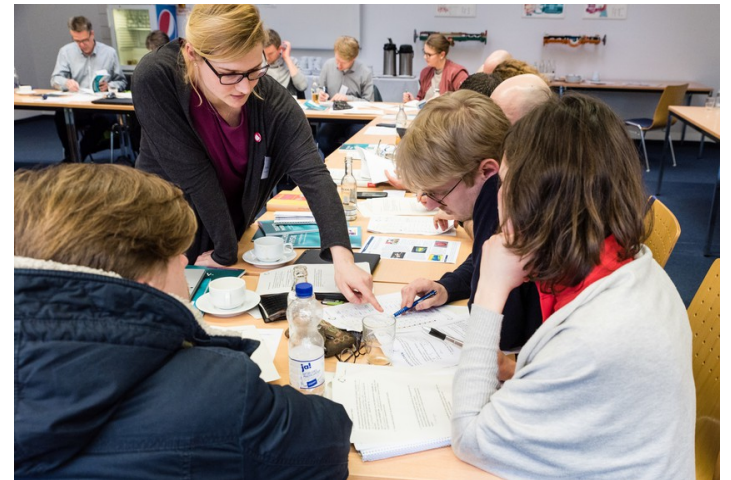

Figure 7: Teacher training from Netzwerk Teilchenwelt (CPhilipp Lindenau)

\section{Funding}

The German Ministry of Education and Research (BMBF) funds HEP research within the current research framework program "Exploration of the Universe and Matter" (ErUM). Netzwerk Teilchenwelt receives funding from this program through a project called KONTAKT. It can thus be stated that outreach has meanwhile become an integral part of research. The aims of the KONTAKT project, in which Netzwerk Teilchenwelt cooperates with the German LHC communication agency "Weltmaschine" [11], are to open up new target groups such as the general public or journalists, to develop new programs and to integrate topics from hadron and nuclear physics.

\section{Conclusion}

Within the framework of Netzwerk Teilchenwelt, scientists are bringing particle physics into the classroom. Young researchers, mostly $\mathrm{PhD}$ students from the participating universities and research institutes, hold events for high school students, such as Masterclasses with data from various experiments. Or they bring detectors to the classrooms which enable students to take their own data and carry out measurements. Each year, around 3.850 pupils take part in the multi-stage program, including 70 high school students being invited to CERN for workshops or to pursue their own research projects. Promising young academics continue to receive support during their studies and stay in close connection with the research groups via a Fellow program.

\section{References}

[1] U. Bilow, Particle Physics Masterclasses: Sharing LHC Research and Discovery with High School Students, in proceedings of ICHEP conference PoS(ICHEP2018) 321.

[2] Netzwerk Teilchenwelt website, https://www.teilchenwelt.de/

[3] Cosmic@Web website, http://physik-begreifenzeuthen.desy.de/offers/cosmic particles/cosmicweb/index eng.html

[4] Jugend forscht website, https://www.jugend-forscht.de/ 
[5] https://www.teilchenwelt.de/mitmachen/fellows/

[6] https://www.teilchenwelt.de/mitmachen/vermittler/

[7] https://www.teilchenwelt.de/material/materialien-fuer-lehrkraefte/unterrichtsmaterialteilchenphysik/

[8] https://www.teilchenwelt.de/fileadmin/user_upload/Redaktion/Netzwerk_Teilchenwelt/Downloads/ Teilchensteckbriefe_engl.pdf

[9] https://www.leifiphysik.de/kern-teilchenphysik

[10] https://www.teilchenwelt.de/angebote/lehrerfortbildungen-forschung-trifft-schule/

[11] Weltmaschine website, https://www.weltmaschine.de/ 